\title{
Proposta para o Cálculo do Coeficiente de Partição Gás/Aerossol de Compostos Orgânicos Voláteis Utilizando Métodos DFT Associados ao Modelo IEFPCM
}

\author{
Leonardo Baptista \& Lillian L. Castilho
}

\section{Introdução}

Já é bem aceito na literatura o fato da composição do aerossol orgânico secundário (SOA) ser composto majoritariamente pelos produtos de oxidação de compostos orgânicos voláteis, como os terpenos emitidos pelas plantas. Por este motivo, encontra-se uma série de trabalhos que tentam caracterizar a composição do SOA, suas fontes, velocidade de particionamento dos compostos entre a fase gasosa e o aerossol líquido e elaboração de modelos para o cálculo dos coeficientes de partição gás/aerossol. Devido a importância do tema para qualidade do ar e saúde dos seres vivos, o presente trabalho propões uma alternativa para o cálculo dos coeficientes de partição gás/aerossol pelo cálculo da energia livre de Gibbs de solvatação usando métodos DFT associados ao modelo IEFPCM para inclusão do efeito do solvente

\section{Metodologia}

O processo estudado no presente trabalho é o particionamento dos produtos de oxidação de terpenos no aerossol atmosférico, como está ilustrado na Figura 1. O parâmetro Kp é o coeficiente de partição gás/aerossol dos produtos de oxidação.

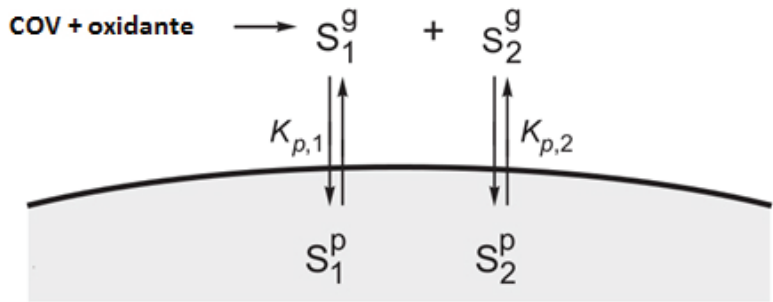

Figura 1: Esquema do particionamento dos produtos de oxidação no aerossol atmosférico e formação do SOA. Adaptado da referência [1].

Os produtos de oxidação do d-limoneno e $\Delta^{3}$-careno ${ }^{2}$ foram escolhidos como o caso de estudo. Inicialmente, uma busca conformacional em fase gasosa foi realizada de para fornecer o conjunto de estruturas possíveis para cada produto de oxidação em fase gasosa. Esta etapa foi feita utilizando dinâmica molecular e o campo de força AMBER. A partir das estruturas iniciais, cada conformação foi completamente otimizada com os funcionais PBE1PBE e M06-2x na base 6-311G*.

Em seguida, todas as conformações foram otimizadas na presença do solvente (água) utilizando o modelo IEFPCM para inclusão do efeito do solvente. A energia livre de Gibbs de solvatação média, 
$\Delta \operatorname{Gav}($ solv), foi calculada via uma média ponderada da energia eletrônica corrigida por ZPE de todas conformações em fase gasosa, considerando que as estruturas obedecem a distribuição de Boltzmann.

O coeficiente de partição gás/aerossol foi calculado segundo um modelo de rede simples

$$
\ln K_{a r}^{\text {aerosol }}=\frac{\mu^{0}(\text { aerosol })-\mu^{0}(a r)}{R T}-\ln \left(\frac{\gamma_{a e r o s s o l}}{\gamma_{a r}}\right)(1)
$$

onde $\mu^{0}$ é o potencial químico do soluto em cada fase e $\gamma$ é o coeficiente de atividade do soluto em cada fase.

\section{Resultados e discussão}

A Tabela 1 apresenta os valores para $\Delta \mathrm{G}_{\mathrm{av}}($ solv)) e $\ln \mathrm{K}_{\mathrm{ar}}^{\text {aerosol }}$ para alguns produtos de oxidação de terpenos. Em uma primeira aproximação foi considerado $\gamma_{\text {aerossol }}=1$. Nesta aproximação, o coeficiente de partição calculado se assemelha ao cálculo da constante da Lei de Henry para os solutos.

Como era de se esperar, devido a formação de compostos oxigenados, todos os compostos são altamente solúveis em água. Logo, espera-se que em uma primeira aproximação, estes compostos sejam encontrados principalmente no aerossol atmosférico ao invés da fase gasosa.

Tabela 1: Energia livre de Gibbs de solvatação média $\left(\Delta \mathrm{G}_{\mathrm{av}}(\right.$ solv $\left.)\right)$ e $\ln \mathrm{K}_{\mathrm{ar}}$ aerosol calculado em nível PBE1PBE/6-311G**.

\begin{tabular}{|c|c|c|}
\hline & $\begin{array}{c}\Delta \mathbf{G}_{\mathbf{a v}}(\mathbf{s o l v}) \mathbf{~ k c a l} \\
\mathbf{m o l}^{-1}\end{array}$ & $\mathbf{I n K _ { \text { ar } }}{ }^{\text {aerosol }}$ \\
\hline Ácido cárico & $-15,46$ & 26,19 \\
\hline Caronaldeído & $-8,77$ & 14,86 \\
\hline Ácido carônico & $-14,91$ & 25,26 \\
\hline Ácido limônico & $-8,30$ & 14,06 \\
\hline Ácido limononico & $-7,92$ & 13,42 \\
\hline
\end{tabular}

O efeito da inclusão da força iônica do aerossol está mostrado na Figura 2. Foram utilizados valores médios da força iônica medida para cada tipo de aerossol ${ }^{3}$. O efeito da concentração de eletrólitos reflete na solubilidade de cada produto de oxidação, diminuindo de forma drástica a solubilidade de cada espécie. O mesmo efeito é observado para os produtos de oxidação do limoneno. Logo, apesar da baixa volatilidade destas espécies, deve-se esperar que estas espécies sejam encontradas em concentração apreciável no aerossol troposférico no aerossol e em fase gasosa.

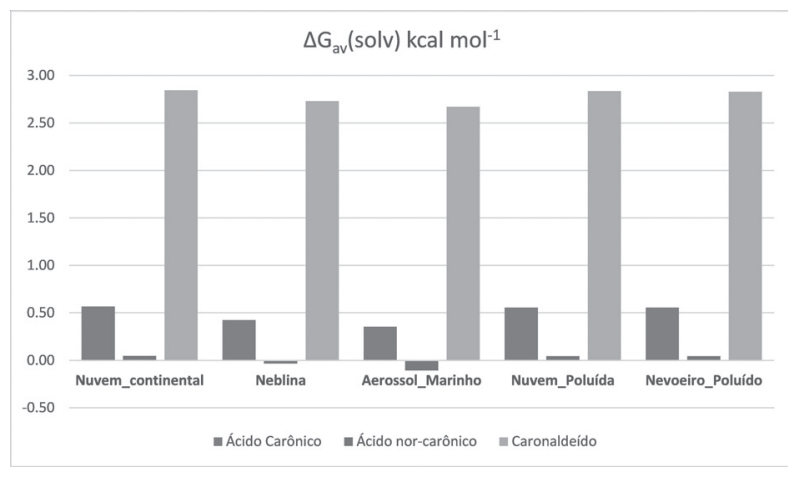

Figura 2: Valores de $\Delta \mathrm{G}_{\mathrm{av}}$ (solv) para os produtos de oxidação do $\Delta 3$ careno calculados em nível PBE1PBE/6-311G**. O efeito do solvente foi incluído por meio do modelo IEFPCM.

O coeficiente de partição para ácido cárico foi calculado por meio da equação (1), considerando $\gamma_{\text {aerossol }}=1$, por se tratar de um gás ideal e $\gamma_{\text {ar }}$ utilizando o modelo AIOMFAC ${ }^{4}$. Para o cálculo foi considerado um intervalo de valores para a fração molar do ácido e as propriedades experimentais do aerossol foram retiradas da referência ${ }^{3}$. A Tabela 2 apresenta os resultados para lnK_ar^aerosol do ácido cárico quando a fração molar deste composto no aerossol é 10-2 em função do tipo de aerossol. Apesar do processo de solvatação ser espontâneo $\left(\Delta \mathrm{G}_{\mathrm{av}}(\right.$ solv $\left.)<0\right)$ para todos os tipos de aerossol considerados, $\ln \mathrm{K}_{\mathrm{ar}}^{\text {aerosol é }}$ negativo. Estes resultados indicam que a presença de íons em solução dificulta a migração do ácido da fase 
gasosa para a fase aquosa. É possível perceber, que a energia livre de solvatação diminui a metade quando é considerado o efeito de eletrólitos em solução aquosa.

Tabela 2: $\operatorname{lnK} \_$ar^aerosol calculado para o ácido cárico utilizando a equação (1) e $\bar{\Delta}$ Gav(solv) em nível PBE1PBE/6-311G**. O efeito do solvente foi incluído por meio do modelo IEFPCM.

\begin{tabular}{|c|c|c|}
\hline & $\begin{array}{c}\Delta \text { Gav(solv) } \\
\text { kcal mol-1 }\end{array}$ & InK $_{\text {ar }}{ }^{\text {arosol }}$ \\
\hline Nuvem continental & $-7,70$ & $-16,40$ \\
\hline Aerossol marinho & $-7,95$ & $-16,47$ \\
\hline Nuvem poluída & $-7,71$ & $-16,09$ \\
\hline Neblina poluída & $-7,72$ & $-16,13$ \\
\hline Chuva & $-7,70$ & $-16,07$ \\
\hline
\end{tabular}

\section{Conclusões e Perspectivas Futuras}

O cálculo da energia livre de solvatação associados ao cálculo de $\ln \mathrm{K}_{\mathrm{ar}}$ aerosol, negligenciando o coeficiente de atividade da fase condensada, para produtos de oxidação de terpenos indicam que estas espécies devem se encontrar majoritariamente no aerossol atmosférico. No entanto, quando se inclui o efeito dos eletrólitos dissolvidos no aerossol, a solubilidade destas espécies é alterada significativamente. Este efeito mostra que as espécies consideradas podem ser encontradas tanto no aerossol atmosférico aquoso, quanto em fase gasosa. No presente momento, cálculo dos coeficientes de atividade para fase aquosa, utilizando o modelo AIOMFAC, estão em andamento. Estes coeficientes possibilitarão o cálculo dos coeficientes de partição para sistemas que emulam condições mais próximas as observadas no aerossol atmosférico.

\section{Agradecimentos}

Os autores agradecem o suporte financeiro do CNPQ e FAPERJ.
3. H. Herrmann, Chem. Rev., 1034691 (2003)

4. http://www.aiomfac.caltech.edu/model.html acessado em 5 de outubro de $\mathbf{2 0 1 5}$

\section{Leonardo Baptista* \& Lillian Lopes Castilho}

Universidade do Estado do Rio de Janeiro, CEP 27537-000, Resende, Brasil

*E-mail: leobap@gmail.com

1. J. H. Kroll, J. H. Seinfeld, Atmos. Environ. 423593 (2008)

2. a) S. Leungsakul et al, Environ. Sci. Technol., 39, 9583 (2005);

b) C. S. Gibson, J. L., J. Simonsen, Chem. Soc., 0, 305 (929) 